A N N A L E S Annales de Bretagne et des Pays de l'Ouest

Anjou. Maine. Poitou-Charente. Touraine

$119-1 \mid 2012$

Varia

\title{
Richelieu. Histoire d'une cité idéale (1631-2011)
}

Manuelle Aquilina

\section{OpenEdition}

Journals

Édition électronique

URL : http://journals.openedition.org/abpo/2355

DOI : $10.4000 /$ abpo.2355

ISBN : 978-2-7535-1852-0

ISSN : 2108-6443

Éditeur

Presses universitaires de Rennes

Édition imprimée

Date de publication : 30 mars 2012

Pagination : 211-212

ISBN : 978-2-7535-1850-6

ISSN : 0399-0826

Référence électronique

Manuelle Aquilina, "Richelieu. Histoire d'une cité idéale (1637-2017) ", Annales de Bretagne et des Pays de I'Ouest [En ligne], 119-1 | 2012, mis en ligne le, consulté le 22 septembre 2020. URL : http:// journals.openedition.org/abpo/2355; DOI : https://doi.org/10.4000/abpo.2355

Ce document a été généré automatiquement le 22 septembre 2020.

(c) Presses universitaires de Rennes 


\title{
Richelieu. Histoire d'une cité idéale (1631-2011)
}

\author{
Manuelle Aquilina
}

\section{RÉFÉRENCE}

Marie-Pierre Terrien, Richelieu. Histoire d'une cité idéale (1631-2011), Rennes, PUR, 2011, 254 p. (ISBN 978-2-7535-1321-1).

1 Voici une recherche qui entend retracer l'histoire d'une ville, celle de Richelieu, et qui, à ce titre, participe de ces nécessaires monographies si utiles aux chercheurs pour effectuer des synthèses d'histoire urbaine. Elle évoque plus précisément les évolutions de la cité de Richelieu à travers les siècles en se focalisant sur les liens qui l'unissent, dès l'origine, à son château et dont la déconstruction a eu sur l'histoire locale de profondes conséquences. L'ouvrage de Marie-Pierre Terrien vient ainsi compléter un précédent livre, paru également aux Presses universitaires de Rennes, en 2009, et consacré au château de Richelieu.

2 La cité de Richelieu naît de la volonté du cardinal de développer, sur ses terres familiales auxquelles il est très attaché, un vaste programme d'urbanisme aussi ambitieux que novateur qui participera, autant que la magnificence du château, à sa propre gloire et à celle de la monarchie qu'il sert. En 1631 le cardinal obtient de Louis XIII l'autorisation de créer un bourg clos de murailles et de fossés. Sa "cité idéale » grandit, comblée de privilèges, ce qui attire les habitants, aux côtés du superbe château auquel elle est indéfectiblement reliée, notamment par un liquide vital pour elle : l'eau. La rivière du Mable approvisionne en eau potable à la fois les douves du château et la fontaine de Bisseuil dont jouissent les habitants de la cité. L'importance accordée par M.-P. Terrien à l'eau, dont elle fait un élément central de son étude, est à la hauteur de l'enjeu que représente pour la cité le contrôle de cette ressource.

3 Après avoir retracé en un chapitre la période de fondation de la cité de Richelieu, en avoir expliqué le plan et son caractère novateur, avoir expliqué ses liens avec le 
château, l'auteure prend le temps, dans un deuxième chapitre, de nous plonger dans le décor si majestueux de la ville. Les exigences urbanistiques de cette dernière répondent à la magnificence du château de Richelieu, largement évoqué, dont la renommée s'étend hors du royaume. Le lecteur appréciera d'emblée la minutie de la reconstitution de la construction de la cité : les diverses archives se conjuguent pour le guider dans la compréhension des choix urbanistiques audacieux effectués au XVII e siècle. Jusqu'à la fin du XVIII ${ }^{e}$ siècle, sous la houlette des héritiers du cardinal, le château comme la cité sont florissants car protégés et maintenus dans leurs privilèges, même si le château est un peu délaissé à partir de 1750. Les très nombreuses archives convoquées, issues des budgets de la cité essentiellement, nous permettent de suivre en détail l'évolution de la vie urbaine. La grande dépendance envers ses seigneurs aussi. Car la ville de Richelieu, sortie de terre ex nihilo, éloignée des grands axes de communication, ne bénéficie pas des atouts favorisant habituellement les naissances urbaines. La période révolutionnaire fait ensuite l'objet d'un chapitre complet, ce qui était nécessaire pour montrer le basculement fondamental qui s'opère alors: les privilèges de la cité s'éteignent, tandis que le château devient bien national puis bien privé et se dégrade. La cité découvre la dure réalité d'une gestion municipale autonome. Puis s'ouvre le long $\mathrm{XIX}^{\mathrm{e}}$ siècle (traité dans deux chapitres copieux) au cours duquel la cité, par l'intermédiaire de ses maires, et le château, aux mains de nouveaux propriétaires, vont non seulement cesser de vivre en symbiose mais s'affronter. Car le lien indéfectible noué par l'eau entre le château et la cité demeure incontournable, si bien que séparer le château de la cité revenait immanquablement à assoiffer peu à peu cette dernière. Acheminée du château par canalisations, l'eau est absolument nécessaire à la vie urbaine (l'importance des fontaines est souvent rappelée) et elle devient donc une pomme de discorde récurrente entre les propriétaires successifs du château et les gestionnaires de la ville. Les premiers jugent l'entretien des canalisations trop coûteux, les seconds considèrent l'acheminement de l'eau depuis le château comme un dû : de là un long procès. Richelieu se trouve également confronté à ses handicaps originels : la ville est implantée dans un territoire de marais, éloignée des grandes routes. Malgré cela, Richelieu, sous la houlette de maires actifs et entreprenants, change peu à peu de visage, se modernise, s'affermit économiquement aussi, grâce à de nombreuses foires. Son histoire rejoint alors celle de l'urbanisme porteur d'hygiène et de modernité du $\mathrm{XIX}^{\mathrm{e}}$ siècle. À la fin de ce siècle, le problème de l'eau est enfin réglé, la cité peut alors entrer de plain-pied dans la modernité. La vie de Richelieu au Xxe siècle, traitée plus rapidement en un court chapitre, semble se conformer aux grandes évolutions de l'histoire des petites villes françaises isolées au milieu de territoires ruraux : le premier vingtième siècle est ainsi marqué par les deux guerres, le second cherche, par la valorisation du passé prestigieux de la cité et de son patrimoine exceptionnellement conservé, à soutenir l'activité de la ville.

Cette étude très documentée, la variété et le nombre des sources convoqués par M.-P. Terrien, qui relèvent tant de l'histoire urbaine que de l'histoire de l'art, sont remarquables et montrent une connaissance approfondie de Richelieu. Nombre de ces sources, conservées aux archives départementales d'Indre-et-Loire et à Richelieu même, étaient jusqu'à présent inexploitées. Une autre des grandes qualités de cet ouvrage repose sur l'iconographie abondante, tout à fait pertinente et bien expliquée, agrémentée de cahiers couleur, ainsi que sur les divers plans, très clairs et très bien exploités, car l'histoire urbaine est faite de plans où se croisent les rues et s'organisent les ilots d'habitations et les places. Cet ouvrage entend couvrir une période très vaste. 
Son ampleur chronologique, si elle explique la rapidité avec laquelle est traitée la période postérieure à 1900, se justifie pleinement du point de vue de la compréhension des évolutions urbaines. La meilleure connaissance de l'originalité de cette cité de Richelieu, de son patrimoine et de son histoire, permettra sans doute de mieux la mettre en valeur au cours de ce nouveau siècle. 